\title{
Students Information System Using Porter's Model
}

\author{
O.T. Adebayo, S.A. Okeowo, F.O. Adebayo \\ The Federal University of Technology Akure (FUTA) \\ Nigeria
}

\begin{abstract}
The adoption of Information systems has presented an avenue for industries to leverage on the unique strength information systems to achieve competitive advantage. Educational institutes are not left behind in the adoption of information systems with the main view of gaining some form of advantage over competitors. Gaining competitive advantage with information system is critical for organizations, the level of competition is determined using Porters five forces. In recent times, as the number of private owned secondary schools increase in a particular geographical area, owners of these private owned secondary schools have embraced the usage of information system in order to gain some level of advantage over their competitors. The management and provision of information about students is an essential part of effective management. Gaining competitive advantage with information system is critical for organizations; the level of competition is determined using Porters five forces. This research work takes a look at the use of Porter's Five Forces, the three generic strategies, and value chains in determining the drivers and the impacts of the adoption of information systems for competitive advantage. The relative attractiveness of these industries was also examined with the aid of Porters five (5) forces. The target population is ten (10) carefully selected privately owned secondary school in Akure. A well-structured questionnaire is administered in these schools and data collected are analysed using frequency distribution, Cronbach Alpha to determine data reliability, Correlation, ANOVA and regression analysis tool.
\end{abstract}

\section{Introduction}

The use of Information System (IS) in an organization assumes a key role in the success of an organization [3]. At the core of every successful organization is information system set up and lined up with business strategies. The act of creating, capturing, organizing, storing, retrieving, analyzing and acting on information are the fundamental activities in every organization. However, in order to make progress through information technologies, they must be aligned and coordinated with business strategies of the firm [4]. In this manner, organizations have understood the centrality and significance of the use Information System in their business technique toolset.

An Information System consists of five basic resources, namely: People, which consists of IT specialists (such as a Database Administrator or Network Engineer) and end-users (such as Data Capture Clerks). Hardware, which consists of all the physical aspects of an information system, ranging from peripherals to computer parts and servers. Software, which consists of System Software, Application Software and Utility Software. Data, which consists of all the knowledge and databases in the IS. Networks, which consists of communication media and network support [8].

Information system has moved toward becoming interlaced with business in an inseparable way and when it is utilized in organizations intensively can bring about long-haul competitive advantage. Competitive advantage according to [5] is characterized as an authoritative ability of an organization to perform better from multiple points of view that competitors find difficult to imitate now and later on.[6] characterizes competitive strategy as the quest for a good competitive position in an industry, with the intent of building a productive, feasible and sustainable position against the forces that decide industry competition.

To provide convenient access to information, a software solution that provides access and management of such information is required. Hence, Student Information System (SIS), is a software targeted at capturing student's information, and organizing, storing, retrieving such information subsequently. Student Information system is a key system in facilitating the management of student's data in secondary and higher institutions. Student's information system usage in decision making purposes as well as other academics task is crucial. Hence the adoption of students' information systems by different schools. Porter's Five Forces Framework is a method for analyzing competition of a business [7]. Porter's Five Forces is a model that identifies and analyzes five competitive forces that shape every industry and helps determine an industry's weaknesses and strengths [9].

The general objectives of this study were to develop a Student Information System for secondary school students as well as analyze the competitive advantage being enjoyed by schools that adopts 
Student Information System using Porter's model as a benchmark. The explicit objectives of this research work are to: develop a student information management system and analyze student Information system adoption using Porter's model.

\section{Literature Review}

Competition has proved to be a critical force in the operation of various organizations regardless of their industry of belongingness [1]. Competition is at the core of existence of firms. This determines the appropriateness of a firm's activities that can contribute to its performance, such as innovations, a cohesive culture, or good implementation [10].

Porter and Millar [6] proposed a model that for a firm to have competitive advantage over another. The firm should create a dominant value for customers by putting a competitive strategy that can establish a productive and manageable position in respect to competitors. As indicated by [3], Information System has the capacity of creating competitive advantage. Information Technology (IT) is something other than PCs and must be considered extensively to envelop the information that business use including a wide range of increasingly merged and connected technologies that process the data [6].

An investigation by [1] concluded that a firm receiving Information system (IS) enjoys development, development, cost decrease, alliance, and differentiation advantages produced by the use of information system (IS). Also, Information System (IS) improves data processing, and leads to effective communication. These qualities could improve Small and Medium Enterprises (SME) competitiveness in international markets and also encourage relationship with different firms inside a similar value chain.

\section{System Analysis and Design}

The student information system web application consists of the step-by-step sequence of interaction between the users of a system. In this paper, the users of the system are the students and the administrator of the system. The Adapted System Architecture is shown in Figure 1 and the Use-case scenario of the system is illustrated in Figure 2.

\subsection{Data Flow}

The administration view describes the basic level of access that the admin of the webpage has. The activities of the admin are illustrated in Figure 3. The Administrator manages a company, school, or other organization. The administrator in the systems varies from school to school, it may be the principal, head teacher or the vice principal. It is solely dependent on how the affairs are being managed in each school. The Dashboard consists of several activities that can be performed by the administrator of the Proposed System. Login provides a level of restriction on who can access which part of the system. It restricts unauthorized person from accessing some functions on the webpage. Functions like Insert, Update, Delete functions can only be accessed by the administrator after proper identification by logging into the administrator panel.

\subsection{Model for the Study}

The dependent variable in this model is the Competitive Advantage while the independent variables are the eight functional area of operation of Information system use in each organization. The model follows a linear function,

$$
y=f(x)
$$

Where: $\mathrm{x}$ is the Extent of Information System use in different functional area of the firm and $y$ is the Competitive Advantage. Functional area of operation of IS in an organization include, Finance and Accounting, Technical Operation, Human Resources, Sales, Marketing, Research and Development, Customer relationship Management, Office Admin.

\section{System Implementation}

This section looks at the components part of the system and how they collaborate to achieve the stated objectives. The analysis and inferences of data gathered are also done. The system is developed to contain various modules with various buttons and links for navigating through the entire systems. The modules are students' registration page and various administrator accesses (add, update, retrieve and delete) students record pages.

\subsection{Student Registration Page}

The registration page affords the student the opportunity of filling in their details. Information regarding their name, admission number, their course of study, the state of origin they belong to, their class as at the time of filling this information as well as uploading a passport photograph for proper and pictorial identification. Information about the parent is also expected to be submitted as at the time of students' registration. The basic information collected pertaining to the parent is the phone number, this would enable easy means of reaching out to the parent if the need arose. After submitting their details on the student registration portal as shown in Figure 4. The submitted data is then accessible from the administrator end. 


\subsection{View Student Information}

This page gives the administrator the opportunity to retrieve single student information through the admission number or a group of students who are related by class they belong to. Details of students belonging to a particular class can be retrieved as shown in Figure 5.

\subsection{Administrator Login Page}

This page is dedicated to the administrator who has certain level of access that includes inserting new student details, modifying the already stored information as well as deleting outdated or unnecessary student information. The interface of logging inside the admin panel is shown in Figure 5.

\subsection{Admin Dashboard}

The dashboard consists of the activities of the administrator and the view is shown below in Figures 6 and 7. The activities that can be performed by the administrator includes inserting new student records, updating an already existing student records if there are any changes in his or her previously submitted information and deleting an obsolete student details from the records.

\subsection{Update Student Records}

There may exist the need to update the student records due to a mistake made in the process of registering the students and a provision is made possible in updating the students record as shown in the Figures 4 to 6 below. The processes leading up to the update of a particular student details include, selecting the class the student belongs to and making necessary updates.

\section{Discussion}

Data gathered from the respondents are analyzed and the results are presented in Tables 1 to 8 (for each section of the questionnaire).

\subsection{Extent of Information System Use}

The research also sought to know the extent that Information System has been used in the different functional areas within the firm. The data collected was mapped on a 5-point Likert Scale with: 1-No extent, 2-Small Extent, 3-Moderate, 4-Great Extent, 5-Very Great Extent. The mean and standard deviation for the extent of IS usage in the firm were also computed and results presented below.

Data in Table 1 shows that respondents were neutral on the extent of the usage of Information system in finance. It has a mean of 2.53 and a standard deviation of 0.99 .

The questionnaire also captured the drivers for the use of Information System for competitive advantage. The data collected was mapped on a 5point Likert Scale with: 1-Strongly Disagree, 2Disagree, 3-Neutral, 4-Agree, 5-Strongly Agree. The means and standard deviation for the drivers for the use of IS were also computed.

From Table 2, it can be observed that the highest mean was 4.27 which represented the use of information system to increase the speed of operation of the firm. This means that most of the respondent Agree that they were driven by the use of IS to increase the speed of operation. The lowest was 2.67 and it represent the use of IS to create barriers for competitors in the same industry.

The questionnaire also captured the challenges for the use of Information System for competitive advantage. The data collected was mapped on 5points using the Likert Scale with: 1-Strongly Disagree, 2-Disagree, 3-Neutral, 4-Agree, 5-Strongly Agree.

The means and standard deviation for the challenges of IS were also computed. The data in Table 3 shows the highest mean as being 3.13 and the lowest being 1.87 . The mean of 3.13 captures increasing cost of supporting IS systems challenge. This challenge has a standard deviation of 1.13. The lowest mean was on being the pioneer in the use of IS.

The questionnaire also captured the impacts of the use of Information System for competitive advantage. The data collected was mapped on a 5point Likert Scale with: 1-Strongly Disagree, 2Disagree, 3-Neutral, 4-Agree, 5-Strongly Agree. The mean and standard deviation for the impacts for the use of IS were also computed.

Data in the Table shows the highest mean as being 4 and the lowest mean as 2.67. The highest mean was on improved decision making and the lowest was on increased cost of entry by the competitors. The highest deviation was 1.28 was on company expansion while the lowest standard deviation was on improved decision making. Reliability was carried out on the data to ascertain the internal consistencies between items on impacts of competitive advantage and the result of the findings is presented below.

Cronbach value of 0.94 clearly indicates that the interrelated items on the impacts of competitive advantage are consistent with one another.

\subsection{Regression Analysis Result}

The R2 of 0.902 implies that $90.2 \%$ of total variation in dependent variable (competitive advantage) can be explained by the independent variable (extent of information system usage). In 
other words, the independent variables can predict the dependent variables (impact of competitive advantage). Table 7 gives the summary of the variance that occurs in the dependent variable, i.e., impact of competitive advantage.

Since P-value $<0.05$, we neglect h0 and conclude that $[\mathrm{F} 8,6, \mathrm{P}$-value $=0.015]$. This suggests that the independent variables (extents of information system use in each functional area of the firm - sales, finance and accounting, technical operations, human resources, marketing, research and development, customer relation, and office administration) can reliably predict the dependent variable (impact of competitive advantage).

\subsection{Coefficients of Independent Variable}

The Table below shows the coefficients of the independent variables and the kind of relationship that exists between the dependent and each of the independent variables. In Table $8,0.68$ is the value of the competitive advantage when all other independent variables are set to 0. From the Beta Coefficients, it can be concluded that research and development, Sales and Office Administration which has a value of $0.879,0.220$ and 0.207 respectively has the highest influence on competitive advantage.

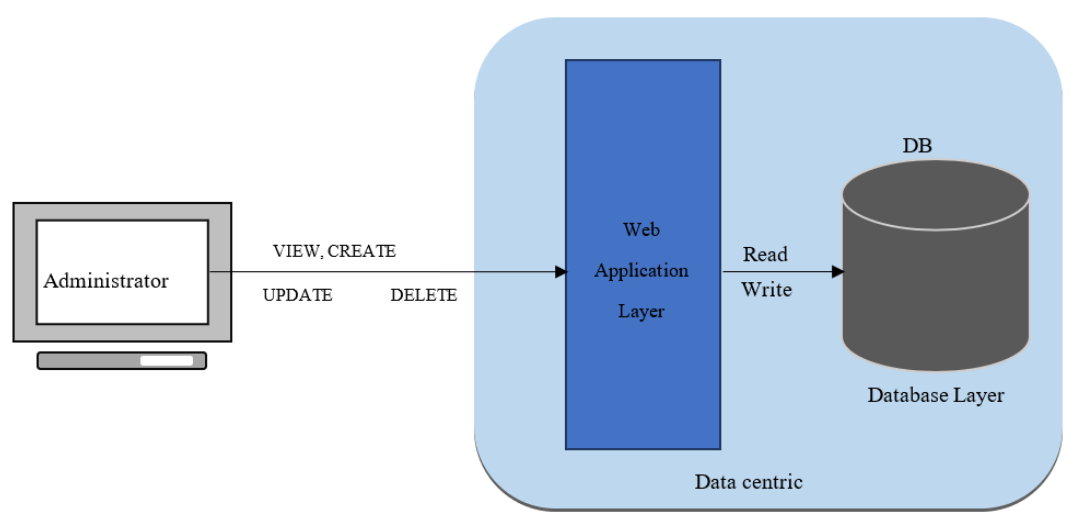

Figure 1: Adapted System Architecture

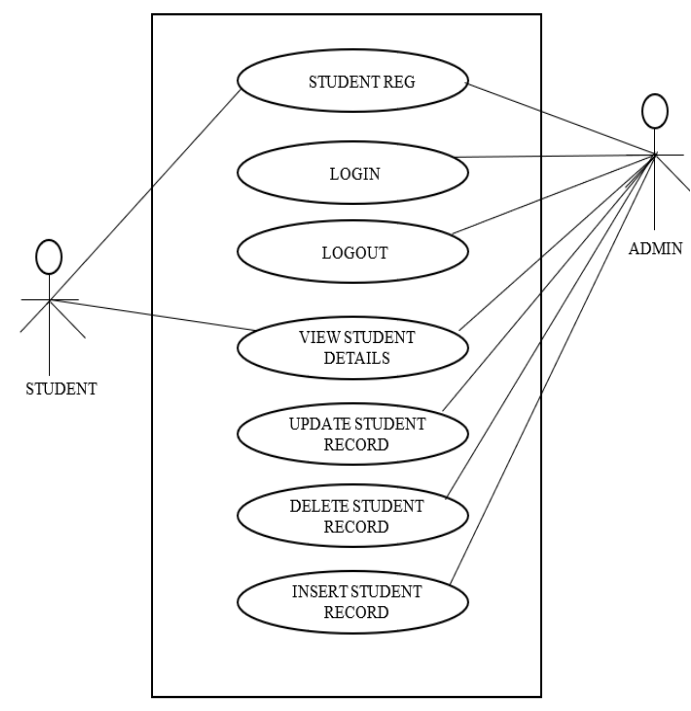

Figure 2: Use-case model of the System 


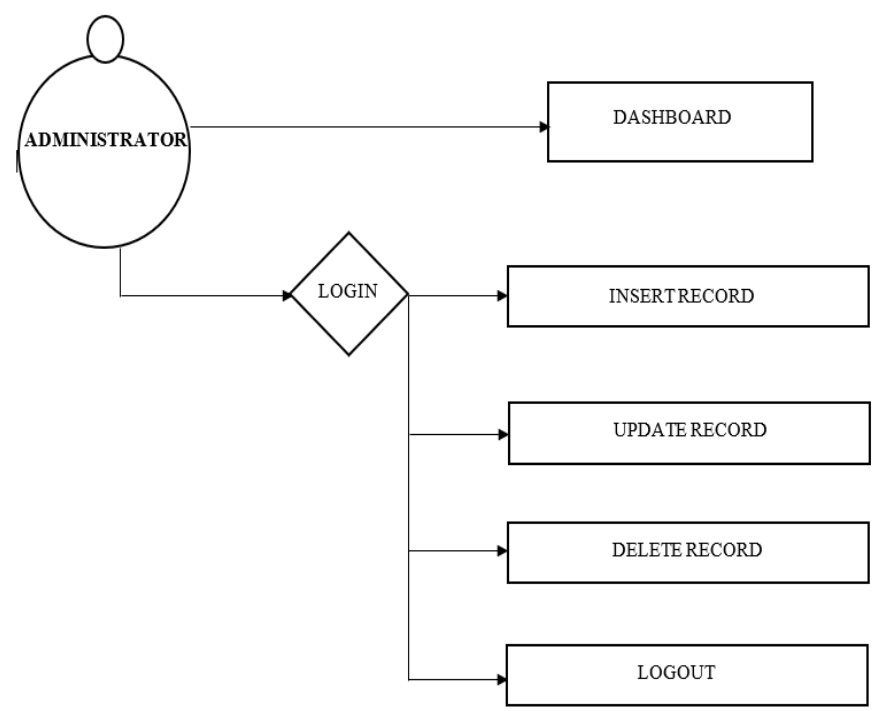

Figure 3: Dataflow of the Proposed System

\section{STUDENT REGISTRATION PORTAL}

\begin{tabular}{l} 
Admin No: \\
Enter your admission number \\
First Name \\
first name \\
Last Name \\
State Please select region. state or province \\
Course: \\
Enter your Course of study \\
Parent Phone No.: \\
Enter Parent Phone No. \\
Student Class \\
\hline Enter Student class \\
Image: \\
\hline Choose File No file chosen \\
INSERT \\
\hline
\end{tabular}

Figure 4: Student Registration 


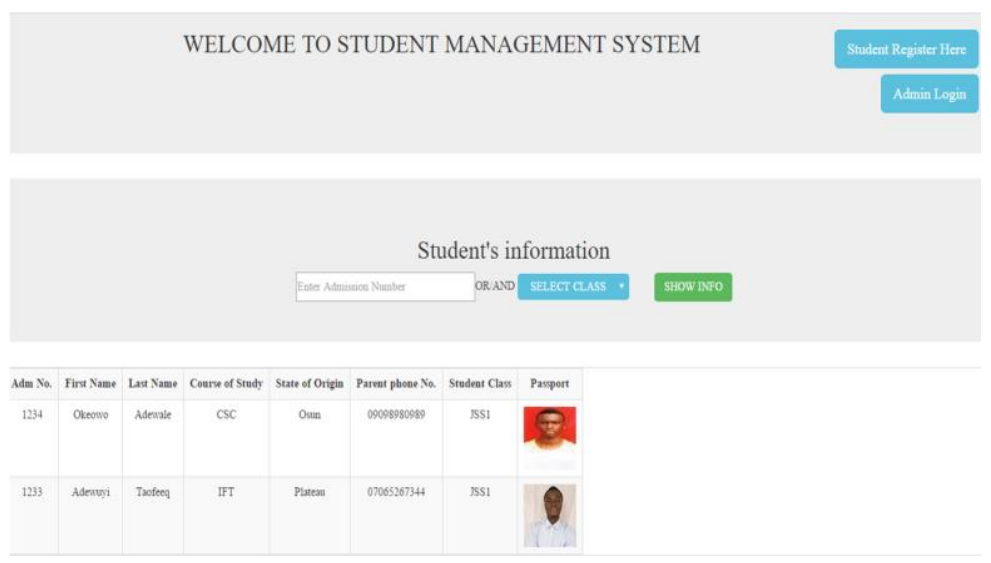

Figure 5: Retrieving Student Details

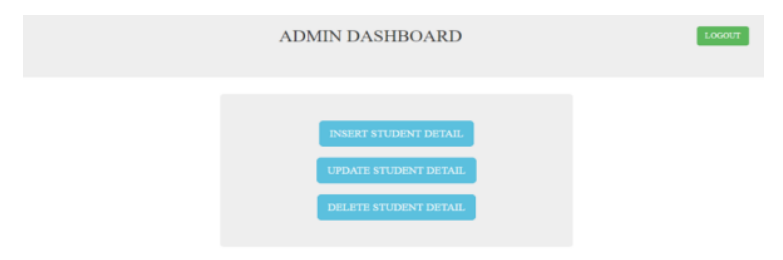

Figure 6: Administrator dashboard

The Figures 4 to 7 are the screen shots of our proposed Students Information System using Porter's Model.

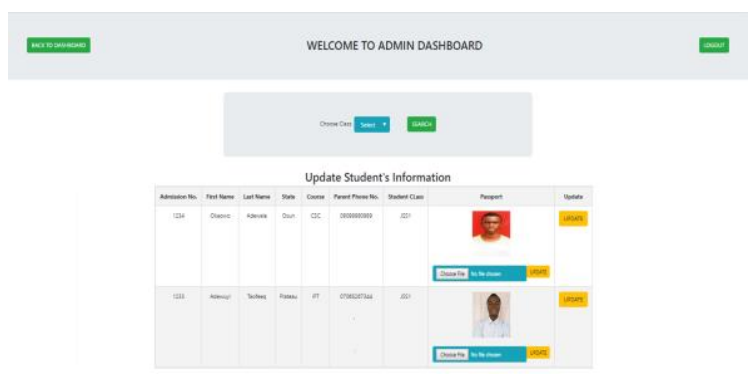

Figure 7: Student record update

Table 1: Extent of Information System Use in Functional Area

\begin{tabular}{|l|c|c|c|c|c|c|c|}
\hline \multicolumn{1}{|c|}{ Functional Area } & $\mathbf{1}$ & $\mathbf{2}$ & $\mathbf{3}$ & $\mathbf{4}$ & $\mathbf{5}$ & MEAN & SD \\
\hline Finance and Accounting & 2 & 6 & 4 & 3 & 0 & 2.53 & 0.99 \\
\hline Technical Operations & 3 & 3 & 5 & 3 & 1 & 2.73 & 1.22 \\
\hline Human Resources & 7 & 3 & 3 & 2 & 0 & 2.00 & 1.13 \\
\hline Sales & 5 & 3 & 6 & 1 & 0 & 2.20 & 1.01 \\
\hline Marketing & 5 & 6 & 3 & 1 & 0 & 2.00 & 0.93 \\
\hline Research and Development & 4 & 6 & 2 & 3 & 0 & 2.27 & 1.10 \\
\hline Customer Relationship Management & 1 & 5 & 5 & 1 & 3 & 3.00 & 1.25 \\
\hline Office Administration & 0 & 0 & 7 & 5 & 3 & 3.73 & 0.78 \\
\hline
\end{tabular}

Data in Table 1 shows that respondents were neutral on the extent of the usage of Information system in finance. It has a mean of 2.53 and a standard deviation of 0.99 .

Table 2: Drivers for Use of Information System for competitive advantage

\begin{tabular}{|c|c|c|c|c|c|c|c|}
\hline Driver & 1 & 2 & 3 & 4 & 5 & MEAN & SD \\
\hline Low Cost of Delivery of products and services & 3 & 2 & 3 & 3 & 4 & 3.20 & 1.52 \\
\hline Delivery of differentiated service & 2 & 3 & 2 & 4 & 4 & 3.27 & 1.53 \\
\hline Innovation & 1 & 3 & 3 & 5 & 3 & 3.40 & 1.24 \\
\hline Focus on specific market Segment & 2 & 2 & 4 & 3 & 4 & 3.33 & 1.40 \\
\hline Reduced competitive disadvantage & 2 & 2 & 3 & 6 & 2 & 3.27 & 1.28 \\
\hline Increase in Productivity & 1 & 1 & 3 & 4 & 4 & 3.73 & 1.16 \\
\hline Increased speed of operation & 0 & 1 & 2 & 4 & 8 & 4.27 & 0.96 \\
\hline Improved quality of products and services & 1 & 2 & 3 & 4 & 5 & 3.60 & 1.24 \\
\hline
\end{tabular}




\begin{tabular}{|c|c|c|c|c|c|c|c|}
\hline Competitive Intelligence & 2 & 3 & 5 & 3 & 2 & 3.00 & 1.25 \\
\hline Improvement on the relationship with Customers and Suppliers & 0 & 3 & 2 & 5 & 5 & 3.80 & 1.15 \\
\hline Lock-in of customers and suppliers & 1 & 5 & 3 & 3 & 3 & 3.13 & 1.30 \\
\hline Generation of Databases to improve marketing & 1 & 4 & 3 & 5 & 2 & 3.20 & 1.21 \\
\hline Creation of Barriers for Competitor Entry & 4 & 3 & 4 & 2 & 2 & 2.67 & 1.40 \\
\hline Establishment of High Switching Cost & 2 & 5 & 4 & 1 & 3 & 2.87 & 1.36 \\
\hline
\end{tabular}

Table 3: Challenges in the Use of Information System for Competitive Advantage

\begin{tabular}{|c|c|c|c|c|c|c|c|}
\hline Challenges & 1 & 2 & 3 & 4 & 5 & MEAN & SD \\
\hline Difficulty in using technology efficiently & 0 & 6 & 3 & 5 & 1 & 3.07 & 1.03 \\
\hline Difficulty in choosing the correct IT framework & 2 & 3 & 6 & 2 & 2 & 2.93 & 1.22 \\
\hline Lack of effective Management of strategies used for CA & 1 & 6 & 5 & 3 & 0 & 2.67 & 0.90 \\
\hline Lack of finances & 3 & 4 & 4 & 1 & 3 & 2.80 & 1.42 \\
\hline Lack of skilled staff & 1 & 6 & 5 & 1 & 2 & 2.80 & 1.15 \\
\hline Lack of ICT infrastructure & 1 & 5 & 7 & 1 & 1 & 2.73 & 0.96 \\
\hline Lack of management support & 3 & 7 & 1 & 1 & 2 & 2.53 & 1.36 \\
\hline Difficulty in measuring IT productivity gains & 1 & 7 & 1 & 4 & 2 & 2.93 & 1.28 \\
\hline Lack of Supporting Technological core & 1 & 3 & 8 & 1 & 2 & 3.00 & 1.07 \\
\hline Lack of a Management framework for IT & 1 & 3 & 8 & 1 & 2 & 3.00 & 1.07 \\
\hline System Implementation Issues & 0 & 5 & 7 & 1 & 2 & 3.00 & 1.00 \\
\hline Lack of IT policy within the organization & 2 & 7 & 3 & 2 & 1 & 2.53 & 1.13 \\
\hline Fear of Being pioneer in use of the technology & 7 & 5 & 2 & 0 & 1 & 1.87 & 1.13 \\
\hline Increasing Cost of supporting the IS & 1 & 3 & 5 & 5 & 1 & 3.13 & 1.06 \\
\hline Minimizing threats and risk to the IS & 1 & 6 & 5 & 2 & 1 & 2.73 & 1.03 \\
\hline Difficulty in using technology optimally & 2 & 6 & 3 & 4 & 0 & 2.60 & 1.06 \\
\hline
\end{tabular}

Table 4: Impacts of the use of Information System

\begin{tabular}{|c|c|c|c|c|c|c|c|}
\hline Impacts of use of IS for Competitive Advantage & 1 & 2 & 3 & 4 & 5 & MEAN & SD \\
\hline Low cost of delivery & 0 & 1 & 5 & 7 & 2 & 3.67 & 0.82 \\
\hline Differentiated services and products & 0 & 2 & 5 & 5 & 3 & 3.60 & 0.99 \\
\hline Improvement on Innovation & 0 & 3 & 5 & 3 & 4 & 3.47 & 1.06 \\
\hline Focus on specific market segment & 0 & 3 & 5 & 5 & 2 & 3.40 & 0.99 \\
\hline Reduced Competitive Disadvantage & 0 & 3 & 3 & 7 & 2 & 3.53 & 0.99 \\
\hline Increase in Productivity & 0 & 3 & 3 & 5 & 4 & 3.67 & 1.11 \\
\hline Increased Switching Costs for Customers & 2 & 4 & 5 & 3 & 1 & 2.80 & 1.15 \\
\hline Lowered Supplier Power & 2 & 3 & 4 & 5 & 1 & 3.00 & 1.20 \\
\hline Lowered buyer Power & 2 & 3 & 5 & 4 & 1 & 2.93 & 1.16 \\
\hline Increased Costs of Entry to industry & 1 & 6 & 6 & 1 & 1 & 2.67 & 0.98 \\
\hline Improved communication and information flow & 0 & 1 & 2 & 5 & 7 & 4.20 & 0.94 \\
\hline Improved decision making & 0 & 0 & 1 & 7 & 7 & 4.40 & 0.63 \\
\hline Company Growth & 0 & 7 & 4 & 2 & 2 & 2.93 & 1.10 \\
\hline Company Expansion & 2 & 4 & 4 & 3 & 2 & 2.93 & 1.28 \\
\hline
\end{tabular}

Table 5: Reliability result

\begin{tabular}{|c|c|}
\hline Cronbach Alpha & No of items \\
\hline 0.940 & 14 \\
\hline
\end{tabular}

Table 6: Model Summary of regression analysis

\begin{tabular}{|c|c|c|c|c|}
\hline Model & R & R Square & Adjusted R Square & Std. Error of the Estimate \\
\hline 1 & $0.950^{\mathrm{a}}$ & 0.902 & 0.772 & 0.37194 \\
\hline
\end{tabular}


Table 7: Summary of analysis of variance of regression

\begin{tabular}{|l|c|c|c|c|c|}
\hline Model & Sum of Squares & df & Mean Square & F & Sig \\
\hline Regression & 7.682 & 8 & 0.960 & 6.941 & $0.015^{\mathrm{b}}$ \\
\hline Residual & 0.830 & 6 & 0.138 & & \\
\hline Total & 8.512 & 14 & & & \\
\hline
\end{tabular}

Table 8: Coefficients of regression analysis

\begin{tabular}{|c|c|c|c|c|c|c|}
\hline \multirow{2}{*}{\multicolumn{2}{|c|}{ Model }} & \multicolumn{2}{|c|}{$\begin{array}{c}\text { Unstandardized } \\
\text { Coefficients }\end{array}$} & \multirow{2}{*}{$\begin{array}{c}\begin{array}{c}\text { Standardized } \\
\text { Coefficients }\end{array} \\
\text { Beta } \\
\end{array}$} & \multirow[b]{2}{*}{$\mathbf{t}$} & \multirow[t]{2}{*}{ Sig } \\
\hline & & B & Std. Error & & & \\
\hline \multirow[t]{9}{*}{1} & (Constant) & .608 & .966 & & .629 & .552 \\
\hline & Finance and Accounting & -.018 & .227 & -.023 & -.081 & .938 \\
\hline & Technical Operations & .056 & .180 & .088 & .312 & .766 \\
\hline & Human Resources & -.082 & .218 & -.119 & -.375 & .720 \\
\hline & Sales & .169 & .176 & .220 & .964 & .372 \\
\hline & Marketing & .065 & .192 & .077 & .339 & .746 \\
\hline & Research and development & .623 & .281 & .879 & 2.219 & .068 \\
\hline & Customer relationship & .050 & .173 & .080 & .289 & .782 \\
\hline & Office Administration & .202 & .178 & .207 & 1.137 & .299 \\
\hline
\end{tabular}

\section{Recommendations}

Based on the numerous benefits of employing Information Systems especially in secondary schools, it is recommended that secondary schools should adopt Information systems as a means of storing the information of their students. As it has been established to give such firm an advantage over other competing firms.

Faster decision-making ability with the aid of a supporting system saves maximum time in pulling out information of students on who the decision is to be made, hence, existing and intending investors are implored to tap into the numerous benefits of IS especially as it regards the administration activities of the enrolled students.

It is also recommended that investors planning to start up a school industry should endeavor to align the adopted information system with their business strategy.

\section{Conclusion}

Student Information System has been seen to play an important tool in the day-to-day activities of schools that adopts IS. Information System (IS) has also been proven from the evaluation carried out that Information System when channeled appropriately with the organization business strategy can be a source of competitive advantage over other competitors in the industry. Information Systems deployed in schools has found its usefulness in office administration of the schools, which in other words, found its application in the decision-making ability of the organization (schools) involved.

Both structured and non-structured decision can be made about students whose information is captured through the Student Information System developed in this research work.

Our research work adds to the body of knowledge on the utilization of Information System for competitive advantage. The added knowledge will be useful to scholars, teachers and researchers in this study are.

The findings of this study will further add more knowledge towards the debate that student Information System can be used for competitive advantage in the education industry. Potential investors who have mindset of establishing schools will have first-hand information on the importance and contribution of Information System to enhance decision making of the organizations and other competitive advantage that can be enjoyed.

\section{References}

[1] Christopher M.I., Mucheru S.M., Evans N.M., Julius M.B. and Gongera E.G., (2014). The Application of Porter's Five Forces Model on Organization Performance: A Case of Cooperative Bank of Kenya Ltd. European Journal of Business and Management www.iiste.org ISSN 2222-1905 (Paper) ISSN 2222-2839, Vol.6, No.16, 2014 75.

[2] Daneshvar, P., and Ramesh, H.N., (2010). Review of Information Technology Effect on Competitive 
Advantage- Strategic Perspective. International Journal of Engineering Science and Technology, 2(11), 6248-6256.

[3] David T. Bourgeois and Bourgeois, (2014). Information Systems and Beyond. https://bus206.pressboo ks.com/font-matter/introduction/. (Access Date: March 11, 2020).

[4] Galliers, R.D., (1993). IT strategies: beyond competitive advantage. Journal of Strategic Information Systems, 2(4), 283-291.

[5] Kotler, P., Filiatrault, P., and Turner, R.E., (2000). Marketing Management (10th Edition). G. Morin.

[6] Porter, M., and Millar, V., (1985). How information gives you firm-level value. Harvard Business Review, 63(4), 149-160.

[7] Porter's five forces ana-lysis, (2020). https://en.wikiped ia.org/wiki/Porter's_five_forces_ana-lysis, (Access Date: 1 2 July, 2020).

[8] Wikipedia, (2020). http://en.wikipedia.org/wiki/Inform ation_system, (Access Date: 25 May, 2020).

[9] Inverstopedia, (2020). Porter's 5 Forces. https://www.in vestopedia.com/terms/p/porter.asp\#: :text=Porter's\%20Fiv e $\% 20$ Forces $\% 20$ is $\% 20$ a $\% 20$ framework $\% 20$ for $\% 20$ analyzi ng\%20a\%20company's,products $\% 20$ influence $\% 20 \mathrm{a} \% 20$ co mpany's\%20profitability. (Access Date: 05 August, 2020)

[10] Mugo, P., (2020). Porter's Five Forces Influence on Competitive Advantage in Telecommunication Industry in Kenya. European Journal of Business and Strategic Management, [S.1.], v. 5, n. 2, p. 30 - 49, Sep. ISSN 2518265X. https://www.iprjb.org/journals/index.php/EJB

SM/article/view/1140>. (Access Date: 5 August, 2020). doi: https://doi.org/10.47604/ejbsm.1140. 